\section{Namen für das Unsagbare}

\author{
E. Taverna
}

Der 1952 verstorbene Landarzt Eduard Renner hat in seinem Buch "Goldener Ring über Uri» das magische Denken der Urner Bergler beschrieben. Ihm war diese Welt nicht Aberglaube, sondern letzter Zeuge eines uralten, faszinierenden Weltbildes. Bergkristalle, Pflanzen, Tiere und Menschen verändern ihre Form, verschwinden und sind plötzlich wieder da, oder sind es gleichzeitig an verschiedenen Orten. Nichts bewahrt den dauernden und festen Umriss, Raum und Zeit sind kein verlässlicher Grund.

Zwanzig Jahre später wurde der Anthropologe Carlos Castaneda zum Kultbuchautor einer Generation, die in den magischen Praktiken eines mexikanischen Zauberers ihre Gegenwelt suchte. Psychedelische Experimente mit LSD und anderen bewusstseinsverändernden Drogen haben seither einen Platz in der Medizin.

Das Magische oder Mystische zu beschreiben ist schwierig. Denn aussergewöhnliche Vorgänge müssen erst eine Sprache finden. Renner hatte eine ethnologische Perspektive. Er konnte und wollte bei allem Respekt nie so sein wie seine Patienten. Er gab mit seinen Worten wieder, was er sah und hörte. Castaneda war hingegen ein Lehrling. Er wollte so werden wie sein Meister und übernahm dessen Sprache und Kultur.

Pioniere und Aussenseiter, die um Anerkennung kämpfen, borgen sich ihr Vokabular beim etablierten "Überbau» ihrer Zeit. Der historische Rückblick macht dies bei den geistigen Heilmethoden besonders deutlich. Diese waren oder sind bis heute exorzistisch, messmerisch-heilmagnetisch, vitalistisch, anthroposophisch, esoterisch, tiefenpsychologisch, ethnomedizinisch, kybernetisch oder physikalisch-energetisch begründet. Die ausgeliehene Sprache wärmt sich an der Autorität des anerkannten Faches, ein oft willkommener Nebeneffekt.

Der Redner im vollen St. Katharinensaal in St. Gallen wurde von der Schweizer Parapsychologischen Gesellschaft eingeladen. Er soll über das geistig-energetische Heilen sprechen, über neue Erkenntnisse der Wissenschaft. Er arbeitet seit Jahren mit einer Heilerin, die über die Körperberührung einen unerklärlichen Zugang zu den vergessenen und verdrängten Erlebnissen der Patientinnen und $\mathrm{Pa}$ tienten hat. Sie spürt traumatische Ereignisse, die sich bei ihr zu Bildern verdichten oder sie zu ungewohnten Handlungen veranlassen, die den Schlüssel zum Verständnis liefern. Fallbeispiele wechseln mit Er- klärungsversuchen. Ungewollt kinderlose Frauen, die nach der Therapie schwanger werden, schmerzende Glieder, die Vergangenes an die Oberfläche holen, Unfälle und erlittene Gewalt als Blockaden eines gesunden Lebens. Aussergewöhnlich sind nicht die Anamnesen und auch die Genesungen sind es nicht. Nicht nachvollziehbar ist die Arbeit der Heilerin. Der Redner forscht nach den Ursachen von Vorgängen, für die es in der fachmedizinischen Sprache noch keine Begriffe gibt. Er lässt sich davon als Chefarzt nicht abbringen, auch wenn Unverständnis und Ablehnung ihm das Leben schwermachen. Seine Sorge ist, dass unsere Medizin den Anschluss an eine Entwicklung verpasst, wie sie amerikanische Spitäler mit ihren "Mind-Body-Soul-Instituten» anbahnen. Leider hören wir wenig Konkretes über die klinikeigenen Studien, dafür um so mehr über mathematische und physikalische Experimente, die das Unerklärte interpretieren sollen. Es sind die oft gehörten Argumente und Zitate, wonach Quantenphysik und Chaostheorie die Welt als unstetig, unbestimmt, unentscheidbar, unwiederholbar und nicht vorhersagbar aufdecken, während die Schulmedizin an ihrem überholten, mechanistischen Modell festklebt. Die Gesetze des subatomaren Bereiches seien auch im Alltag gültig, wie die Biophotonenforschung und der Nachweis mentaler Beeinflussung von Zufallsgeneratoren bewiesen. Kohärentes Licht aus Körperzellen vermittle Informationen wie gepulste Laserstrahlen. Als Nichtphysiker kann ich die Behauptungen nicht überprüfen. Die ohnehin überzeugten Zuhörer brauchen diese "Beweise» nicht. Sie sind Gläubige und hören es gerne, wenn der Redner die etablierte Medizin kritisiert. Seine Lichtmetaphorik abstrahlender und aufnehmender Hände führt ihn zur Physik gewaltiger Energiefelder aus dem Vakuum, die auch das geistige Heilen, als eine für jeden Menschen erlernbare Fähigkeit, erklären sollen. Gelassenheit und Liebe versetzen Berge. Wenn wir unsere Herzen für diese Energien öffnen, sind einige Hochbegabte unter uns auch fähig, Löffel $\mathrm{zu}$ verbiegen und Pflanzen verdorren zu lassen.

Dem Redner ist hoch anzurechnen, dass er mit Ausdauer und innerem Feuer einer Wirklichkeit nachspürt, für die es keine Koordinaten gibt. Skepsis bleibt, wo aus fachfremden Analogieschlüssen eine Beweisführung konstruiert wird. Die wissenschaftliche Forschung arbeitet nicht, wie die Kunst, mit einer assoziativen Symbolsprache. Bekanntlich folgt der kurzen Inspiration die langdauernde Transpiration mühsamer, nachvollziehbarer Experimente.

Die 19. Basler Psi-Tage werden Ende November für "Geistiges Heilen und mehr Geist im Gesundheitswesen" werben. Auch Uri Geller wird dort als aussersinnliches und psychokinetisches Talent seine "mind medicine" vordemonstrieren. Die akademische Sparte der menschlichen Anatomie war einst auch ein Jahrmarktthema. Wo sich Ärztinnen und Ärzte auf Technik und Ökonomie reduzieren lassen, sucht der Geist unterhaltsamere Partner. 